\title{
Effects of Modifying Agents on the Dyeability of Cotton Fabric using Malachite Green Dye
}

\author{
Isah A. Bello, Olugbenga S. Bello, Kayode A. Adegoke* \\ Department of Pure and Applied Chemistry, Ladoke Akintola University of Technology. P.M.B 4000, Ogbomoso, Oyo State, Nigeria. \\ Received $13^{\text {th }}$ May 2016, Accepted $27^{\text {th }}$ August 2016 \\ DOI: 10.2478/ast-2018-0005 \\ *Corresponding author \\ Kayode A. Adegoke: kwharyourday@gmail.com
}

\begin{abstract}
Changes in thermodynamic parameters as a result of modifying agents on dye uptake of cotton fabric using malachite green (MG) dye was investigated in this study. Five modifying agents Acetic acid $\left(\mathrm{CH}_{3} \mathrm{COOH}\right)$, hydrated Sodium carbonate $\left(\mathrm{Na}_{2} \mathrm{CO}_{3} \cdot 10 \mathrm{H}_{2} \mathrm{O}\right)$, Sodium Chloride $(\mathrm{NaCl})$, Ammonium sulphate $\left(\left(\mathrm{NH}_{4}\right)_{2} \mathrm{SO}_{4}\right)$ and Hydrogen peroxide $\left.\left(\mathrm{H}_{2} \mathrm{O}_{2}\right)\right\}$ were used on cotton fabric. The equilibrium exhaustions $(\% \mathrm{E})$ were determined before and after modification of the cotton fabric at different concentrations which were $88.24 \%, 80 \%, 77.14 \%, 65.10 \%$ and $30.88 \%$ for $\mathrm{CH}_{3} \mathrm{COOH}, \mathrm{NaCl}$, $\left(\mathrm{NH}_{4}\right)_{2} \mathrm{SO}_{4}, \mathrm{Na}_{2} \mathrm{CO}_{3} \cdot 10 \mathrm{H}_{2} \mathrm{O}$ and $\mathrm{H}_{2} \mathrm{O}_{2}$ respectively. The results also showed a correlation between the standard affinity $\left(-\Delta \mu^{\theta}\right)$ of dye on cotton fabric and the equilibrium exhaustion. The values of entropy $\left(\Delta \mathrm{S}^{\theta}\right)$ and enthalpy $\left(\Delta \mathrm{H}^{\theta}\right)$ change revealed the feasibility (spontaneity) and exothermic nature of the reaction. The optimum parameters were attained in acidic solution $\left(\mathrm{CH}_{3} \mathrm{COOH}\right)$ at the highest temperature $\left(70{ }^{\circ} \mathrm{C}\right)$ of dyeing as it showed the highest \% efficiency of $88.24 \%$. This work established that modification of cotton fabric with modifying agents is one of the best route to improve the affinity between dye and fabric as it reduces stress, amount of dyes wasted in dyeing, time required to achieve satisfactory results leading to a cost effective environmental friendly approach in the field of cotton dyeing.
\end{abstract}

Keywords: Exhaustion; Modifying agents; Malachite green; Cotton; Thermodynamics parameters. 


\subsection{Introduction}

Owing to the vast growth in textile industry, modification of individual fiber types has been developed to broaden uses. Modified fibers can be produced by chemical alteration of the polymer fiber or fabric or by the use of non-reacting additives. Improved dye-ability is usually effected by use of a suitable comonomer (Sundrarajan et al., 2012, Salah and El-Badry 2012, Shahin 2015). These chemicals add value to the contton fabric by transforming the cotton fabric handle to match the customer perception. (Kamel et al., 2007, 2009, El-Molla et al., 2011, Fang et al., 2013, Wang and Liu 2014).

Cellulosic fiber possesses inherent attractive bulk properties but surface modifications are used to diversify its end uses (Baltazar et al., 2007, Termerman and Leys 2007 Mahbubul and Khan 2013, Wang and Liu 2014, Shahin 2015). The dyeing of cellulose fibers with cationic dyes (for instance Malachite green dye) suffers from two major disadvantages; one is poor dye uptake and the other is unsatisfactory dye fixation. Due to poor dye uptake, the exhaustion of unmodified cotton fabric on cationic dye is limited (lesser) and time-consuming than the one obtained for modified cotton fabric. Consequently, the effluents become more concentrated with dye and their discharge to the receiving bodies becomes problematic to human health. In the case of poor dye fixation, the contributing factor is the presence of inactive hydrolyzed dye. In order to overcome this problem, modification of cotton before dyeing was studied so as to ensure increase dye uptake on cotton fabric. Modification of cotton is emerging as an effective tool to solve environmental problems associated with dyeing of cotton

The purpose of physical and chemical procedures for modification of cellulose fibers is to increase reactive dye exhaustion and fixation degree and saving electrolytes. The pretreatment to improve functionality and dyeing ability of cellulose fibers, using cationic agents, has attracted attention recently (Hasani et al., 2009, Liu et al., 2007, Hyde et al., 2007, Mahbubul and Khan 2013, Wang and Liu 2014, Mansour et al.,2014, Fang et al., 2015,). The reason for such treatment is improvement of cationic activities of cellulose fibers and reduction of electrostatic repulsion of negative ions resulting in a positive effect on absorption of anionic dyes and poly electrolytes. Recently, Xie et al., (2007, 2008) reported the chemical, structural and morphological changes of cotton after treatment with triazine derivatives containing cationic and anionic groups and the effects of the treatment on dyeing with reactive dyes. Epoxy compounds (Xie et al., 2008), chlorotriazine type quaternary compounds (Ma et al., 2005), Nmethylolacrylamide (Tutak and Ozdmir 2011), chloline chloride (Michel et al., 2002), chloloroacetic acid etc. are the monomers commonly used in modification of cotton fiber. Due to the smaller molecular size, these compounds present good penetrability in fiber, and the exhaustion and fixation of reactive dyes on the modified fiber have improved. A number of changes are identified on modified cotton: formation of new molecular

structures containing cationic and anionic groups, very low reduction of crystallinity degree, and modification of surface morphology. Modified cotton was dyed with reactive dyes and a higher exhaustion and fixation degree of reactive dyes was achieved as a result of reaction with new groups. The increased yield of reactive dye on cotton fabrics treated with commercial cationic agent is explained by positive surface charge of cationized cotton fiber (Tutak and Ozdmir 2011, Wang and Liu 2014).

In the dyeing process a solution of the dye is made, and the material to be dyed, called the substrate, is put in the solution. Coloured matter from the solution is transferred to the substrate by the process of adsorption; the removal of the dye from the solution is called exhaustion. This is a general description of all dyeing processes. In some cases, dyeing assistants are added to the dye solution to facilitate the interaction of a particular type of dye with the substrate, these are called modifying agents.

Malachite green (MG) is most commonly used for the dyeing of cotton, silk, paper, leather and also in manufacturing of paints and printing inks. Malachite green is widely used in distilleries for colouring purposes (Khattri et al., 1999, Igwe et al., 2008; Gharbani et al., 2008; Goyal et al., 2008; Shah et al., 2009; Zvinowanda et al., 2009, Mahbubul and Khan 2013). Malachite green dye is basically a cationic dye. It has properties that make it difficult to remove from aqueous solutions and also toxic to major microorganisms (Papinutti et al., 2006). Its discharged into receiving streams will affect the aquatic life and causes detrimental effects in liver, gill, kidney, intestine, gonads and pituitary gonadotrophic cells (Srivastava et al., 2004). Therefore, the treatment of effluent containing such dye is of interest due to its esthetic impacts on receiving waters.

The aim of this research work is to ascertain the optimum parameters that will ensure the fastness of the dye on cotton fabrics using different modifying agents especially the common reagents that are readily available but often used for other purposes (such as buffer, leveling agents, etc) in the dyeing industries. To the best of our knowledge, nobody has ever reported the utilization of Acetic acid $\left(\mathrm{CH}_{3} \mathrm{COOH}\right)$, hydrated Sodium carbonate $\left(\mathrm{Na}_{2} \mathrm{CO}_{3} \cdot 10 \mathrm{H}_{2} \mathrm{O}\right)$, Sodium Chloride $(\mathrm{NaCl})$, Ammonium sulphate $\left(\left(\mathrm{NH}_{4}\right)_{2} \mathrm{SO}_{4}\right)$ and Hydrogen peroxide $\left(\mathrm{H}_{2} \mathrm{O}_{2}\right)$ as modifying agents for cotton fabrics in order to achieve salt free dyeing when using Malachite green dyes.

\subsection{Materials and Method}

\subsection{Chemicals}

All chemicals used were of analytical grade. Modifying agents were Acetic acid $\left(\mathrm{CH}_{3} \mathrm{COOH}\right)$, Hydrated sodium carbonate $\left(\mathrm{Na}_{2} \mathrm{CO}_{3} \cdot 10 \mathrm{H}_{2} \mathrm{O}\right)$, Sodium Chloride $(\mathrm{NaCl})$, Ammonium sulphate $\left(\mathrm{NH}_{4}\right)_{2} \mathrm{SO}_{4}$ and Hydrogen peroxide $\left(\mathrm{H}_{2} \mathrm{O}_{2}\right)$. The cationic dye (Malachite green) was selected in the present study.

\subsection{Modification of Cotton}

Cotton fabric obtained from a market in Ogbomoso, Oyo State Nigeria was used in the investigation. The modification process was carried out as follows. Cotton was treated with aqueous 
solution of acetic acid $\left(\mathrm{CH}_{3} \mathrm{COOH}\right)$, hydrated sodium carbonate $\left(\mathrm{Na}_{2} \mathrm{CO}_{3} \cdot 10 \mathrm{H}_{2} \mathrm{O}\right)$, Sodium Chloride $(\mathrm{NaCl})$, ammonium sulphate $\left(\mathrm{NH}_{4}\right)_{2} \mathrm{SO}_{4}$ and Hydrogen peroxide $\left(\mathrm{H}_{2} \mathrm{O}_{2}\right)$ at different concentrations for a fixed time period of 40 minutes in a slack condition as reported previously (Bello et al., 2002, Bello et al., 2014). $1 \% \mathrm{v} / \mathrm{v}$ solution of each modifying agents were measured into a modification bath and make up to $10 \mathrm{~cm}^{3}$. Each stripe of $0.1 \mathrm{~g}$ cotton fabric was inserted into it, covered with aluminum foil paper in order to keep the volume constant throughout the period of modification and cotton fabric was allowed soak on its own for a period of 40 minutes.

\subsection{Preparation of Standard Dyes Solution}

The Malachite green dye, IUPAC name 4-\{[4-dimethylamino)phenyl]( phenyl)methylidene - $\mathrm{N}, \mathrm{N}$-dimethylcyclohexa-2,5diene-1-iminium Chloride $\left(\mathrm{C}_{23} \mathrm{H}_{25} \mathrm{~N}_{2} \mathrm{Cl}\right)$ with molecular weight $364.911 \mathrm{~g} / \mathrm{mol}$ was obtained from S.D fine Chemical, Limited, Mumbai, India. An accurately weighed quantity of $1 \% \mathrm{w} / \mathrm{v}$ dye solution was prepared by dissolving $1 \mathrm{~g}$ of malachite green dye in distilled water and made up to $100 \mathrm{~cm}^{3}$ in a standard volumetric flask (Bello et al., 2002; Bello et al., 2009). All other solutions series of four or five in a dye-bath with $0.1 \mathrm{~g}$ of cotton fabric inserted in each of them. These are then placed in hot water bath with the open end of each dye-bath covered with aluminum foil paper in order to keep the volume of the dye constant throughout the dyeing period. The dyeing was carried out at varying temperatures $(323 \mathrm{~K}, 333 \mathrm{~K}$ and $343 \mathrm{~K})$ with different batch of dyebath at the same concentration for the minimum of 1 hour for each bath. After dyeing, the cotton fabric was then removed immediately from the dye-bath and the solution was allowed to cool after which the absorbance $\mathrm{A}_{\mathrm{T}}$ was taken.

\subsection{Measurement of Absorbance}

The absorbance of the standard solution of the dyes (1\%) were scanned between $400-700 \mathrm{~nm}$ to determined their $\lambda_{\max }$ using UVVIS spectrophotometer (Bello et al., 2009, 2014). Distilled water gotten from Aquamat model V4.60 water distillation apparatus was used as blank to calibrate the spectrophotometer to zero absorbance. The absorbance of each sample were taken

\subsection{Estimation of Percentage Exhaustion (\% E)}

Exhaustion was the total amount of dye taken up by cotton fabrics, which was measured by sampling the dye bath at the beginning and the end of the dyeing process. This was done by removing a dye-bath away from the water bath and the cotton fabric also withdrawn from the bath. The dye-bath was cooled and the residual dye solution was filtered after dyeing and optical density measured at maximum wavelength corresponding to maximum, absorbance namely $\lambda_{\max }=619 \mathrm{~nm}$ (experimentally obtained). The optical density of the original dye-bath solution before dyeing was also measured. From these two measurements, the percentage dye bath exhaustion of the dyed cotton fabric (i.e. cotton) was calculated using the equation (Kawee and Papapida 1998; Bello et al., 2002; Bello et al., 2009, Bello et al., 2014). were prepared from the standard solutions of the dyes.

\subsection{Preparation of Dye Bath}

A $1 \% \mathrm{w} / \mathrm{v}$ dye solution was prepared as stated previously. $0.100 \mathrm{~g}$ of bleached cotton fabric was dyed in each case to $1 \%$ depth by conventional methods (Bello et al., 2002 Bello et al., 2014). The liquor to cotton fabric ratio was 150:1 for different period of equilibrium exhaustion of the dye (Bello et al., 2002). The recipe for the dye bath of 150:1 liquor to cotton fabric ratio is as given below:

Dye Stock Solution 1\% w/v:

Volume of the dye $=0.1 \mathrm{~cm}^{3}$, Mass of cotton fabric $=0.100 \mathrm{~g}$, Water $=14.8 \mathrm{~cm}^{3}$, Total $=15.0 \mathrm{~cm}^{3}$

\subsection{Dyeing}

Basically, all types of textiles fibers are dyed using batch method of dyeing. These methods are dictated primarily by the physical properties of the textiles and the types of fiber it contains. Dye bath of the solution was prepared in triplicate and sometimes in ut

$$
\% E=\frac{A_{o}-A_{t}}{A_{o}} \times 100
$$

Where $A_{0}$ is absorbance at time zero (i. e. before dyeing), $A_{t}$ is absorbance at time t, (i. e. after dying).

\subsection{Determination of Partition Coefficient (K)}

Partition Co-efficient $(\mathrm{K})$ is the ratio of the amount of dye absorbed by the cotton fabric to the amount of dye in the dye-bath at equilibrium (Bello et al., 2002; Bello et al., 2009). It is expressed mathematically as;

$$
K=\frac{[D]_{f}}{[D]_{b}}
$$

where $[D]_{\mathrm{f}}$ is the concentration of dye in the fiber $(\mathrm{g} / \mathrm{kg})$ when equilibrium is attained at dyeing temperature, T. $[D]_{b}$ is the concentration of dye in the residual bath dye $(\mathrm{g} / \mathrm{l})$ when equilibrium is attained at dyeing temperature $\mathrm{T}$.

Partition Co-efficient $(\mathrm{K})$ and percentage exhaustion are related by the equation (Bello et al., 2002, 2009).

$$
\begin{aligned}
& K=\frac{\text { LiquorRatio }}{Q} \times \% E \\
& \text { LiquorRatio }=\frac{\text { volumeofdyebath }}{\text { massoffiber }}=\frac{15 l}{0.1 \mathrm{~g}}=150 \mathrm{lg}^{-1} \\
& Q=100-\% E
\end{aligned}
$$


where $\mathrm{Q}$ is the amount of dye left in the solution at the equilibrium exhaustion and $\% \mathrm{E}$ is the percentage equilibrium exhaustion. In this case, the liquor ratio used is 150:1 liquor to fabric. The above recipe was used throughout this work. For 150:1 liquor ratio, K now becomes (Bello et al., 2002; 2009);

$$
K=\frac{150 \times \% E}{100-\% E}
$$

\subsection{Estimation of Thermodynamic Parameters.}

\subsubsection{Standard Affinity $\left(-\Delta \mu^{\theta}\right)$}

It is the measure of the driving force in any dyeing process. Dyeing of cotton with the malachite green (MG) dye corresponds to the partition mechanism, and hence the standard affinity $\left(-\Delta \mu^{\theta}\right)$ of the dyes for cotton fabric was calculated using the following equation (Bello et al., 2002; Bello et al., 2009)

$$
-\Delta \mu^{\theta}=R T \ln ^{\left[D_{f}\right]} /\left(V \times\left[D_{b}\right]=R T \operatorname{Tin} K_{v}\right.
$$

where $\mathrm{R}$ in the universal gas constant in $\left(\mathrm{kJ} \mathrm{K}^{-1} \mathrm{~mol}^{-1}\right)$; $\mathrm{T}$, the temperature of dyeing in Kelvin $(\mathrm{K}) ;\left[\mathrm{D}_{\mathrm{f}}\right]$, the concentration of dye in the fiber $\left(\mathrm{g} / 100 \mathrm{~g}\right.$ of the cotton fabric); $\left[\mathrm{D}_{\mathrm{s}}\right]$, the concentration of dye in solution $(\mathrm{g} / \mathrm{L}) ; \mathrm{v}$, the colcine term represents the effective volume of water in the substance and $\mathrm{K}$ is the Partition co-efficient $(\mathrm{L} / \mathrm{kg})$.

\subsubsection{Enthalpy Change $\left(\Delta H^{\theta}\right)$ of Dyeing}

The $\Delta \mathrm{H}^{\theta}$ and $\Delta \mathrm{S}^{\theta}$ were calculated using the following equation;

$$
-\Delta \mu^{\theta}=\Delta \mathrm{H}^{\theta}-T \Delta S
$$

The enthalpy change $\Delta \mathrm{H}$ in dyeing process is obtained from the empirical plot that shows the relationship between $\Delta \mu^{\theta} / \mathrm{T}$ and1/T using Eq. 8.

$$
\begin{aligned}
& \Delta \mathrm{H}^{\theta}=\delta\left(-\Delta \mu^{\theta} / \mathrm{T}\right) / \delta(1 / T) \\
& \frac{\Delta \mathrm{H}^{\theta}}{T}=-\Delta \mu^{\theta} / \mathrm{T}+C
\end{aligned}
$$

where $\Delta \mathrm{H}$ is Heat of Adsorption $\left(\mathrm{kJ} \mathrm{mol}^{-1}\right) ;-\Delta \mu^{\theta}$ is Standard Affinity $\left(\mathrm{kJ} \mathrm{mol}^{-1}\right)$; T, Absolute Temperature (K); and C , Integral Constant.

\subsubsection{Entropy of dyeing $\left(\Delta S^{0}\right)$}

This is the rate of disorderliness of the reaction system. $\Delta \mathrm{S}^{\theta}$ was determined by using the relation below;

Dividing equation (3.8) through by $-\mathrm{T}$

$$
\frac{-\mu^{\theta}}{T}=\frac{-\Delta \mathrm{H}^{\theta}}{\mathrm{T}}+\Delta S^{\theta}
$$

A plot of $\Delta \mu^{\theta} / \mathrm{T}$ against $\mathrm{T}^{-1}$ gives a straight line graph where $\Delta \mathrm{H}^{\theta}$ is the slope of the graph and $\Delta \mathrm{S}^{\theta}$ is the intercept of the graph.

\subsection{Results and Discussion}

\subsection{Dyeing Without Modification}

Table 2 showed the results of $\% \mathrm{E}, \mathrm{K}$, and $\Delta \mu^{\theta}$ of cotton dyed with malachite green at different temperature without modification. Fig. 1 revealed the Percentage Equilibrium Exhaustion (\% E) of cotton fabric dye without the use of any modifying agent and the equilibrium were reached at different time for different temperature.

For example, dyeing process at $323 \mathrm{~K}, 333 \mathrm{~K}, 343 \mathrm{~K}, 353 \mathrm{~K}, 363$ $\mathrm{K}$ and $373 \mathrm{~K}$ have the $\% \mathrm{E}$ are $10.11 \%, 12.80 \%, 12.90 \%, 18.50 \%$ $18.60 \%$ and $18.60 \%$ respectively. was that the penetration of dye molecule onto cotton fabric was small which could be as result of insufficient attacking sites between the unmodified cotton fabric and the Malachite Green dye. The thermodynamic parameters obtained were: partition coefficient $(\mathrm{K}): 16.87 \mathrm{~L} \mathrm{~kg}^{-1}, 19.30 \mathrm{~L} \mathrm{~kg}^{-}$ 1, $22.22 \mathrm{~L} \mathrm{~kg}^{-1}, 34.05 \mathrm{~L} \mathrm{~kg}^{-1}, 34.28 \mathrm{~L} \mathrm{~kg}^{-1}$ and $34.28 \mathrm{~L} \mathrm{~kg}^{-1}$ respectively while standard affinities $\left(\Delta \mu^{\theta}\right)$ were $7.6 \times 10^{3} \mathrm{~kJ} \mathrm{~mol}^{-1}$, $8.2 \times 10^{3} \mathrm{~kJ} \mathrm{~mol}^{-1}, 8.8 \times 10^{3} \mathrm{~kJ} \mathrm{~mol}^{-1}, 1.06 \times 10^{4} \mathrm{~kJ} \mathrm{~mol}^{-1}, 1.07 \times 10^{4} \mathrm{~kJ}$ $\mathrm{mol}^{-1}, 1.09 \times 10^{4} \mathrm{~kJ} \mathrm{~mol}^{-1}$ respectively.

\subsection{Effects of Modifying Agents on Cotton Fabric}

It was observed during exhaustion dyeing process that the dyeing uptake of cotton fabric without modification was low. However, when the fabric was modified, the dye uptake of modified cotton fabric was observed increased significantly. Tables 3 and Figures 2 show the results obtained at different concentration of modifying agents and $\% \mathrm{E}, \mathrm{K}, \Delta \mu$ values with different modification reagents concentrations. The high values of $\mathrm{K}$ may probably due to higher volume of dye bath (150:1) which led to faster rate of migration of dye molecules to the fiber hence high uptake of the dyes molecules by the cotton fabric. It has been reported that the values of $\mathrm{K}$ can be used to predict the fastness properties of dyes to the fibers (Bello et al., 2002).

Consequently, the dyeing behaviour of cotton as rendered by the reaction of various modifying agents and result reflect an increase in the mobility of the large dye ions with temperature and thus an increase in the number of molecules interacting with the active sites at the surface. Hence, the application of modification agents on the fibers therefore enhanced a rapid dye uptake by the fiber thereby improved dye exhaustion. It can also be deduced here that $\mathrm{CH}_{3} \mathrm{COOH}$ gave the highest $\% \mathrm{E}$ with respect to $1 \% \mathrm{v} / \mathrm{v}$. This observation is similar to many other works reported in the literature (Kawee and Papapida, 1998; Bello et al., 2002; Zhang, 2005; Bello et al., 2013, Bello et al., 2014). 
Table 1: Dyeing parameters (\% E, K and $\left.\Delta \mu^{\theta}\right)$ of MG dye onto cotton fabric without modifying agent

\begin{tabular}{|c|c|c|c|c|c|c|c|c|c|}
\hline \multirow{2}{*}{ Modifying agents } & \multicolumn{3}{|c|}{$\% \mathrm{E}$} & \multicolumn{3}{c|}{$\mathrm{K}\left(\mathrm{L} \mathrm{kg}^{-1}\right)$} & \multicolumn{3}{c|}{$\Delta \mu^{0}\left(\mathrm{~kJ} \mathrm{~mol}^{-1}\right)$} \\
\cline { 2 - 10 } & $323 \mathrm{~K}$ & $333 \mathrm{~K}$ & $343 \mathrm{~K}$ & $323 \mathrm{~K}$ & $333 \mathrm{~K}$ & $343 \mathrm{~K}$ & $323 \mathrm{~K}$ & $333 \mathrm{~K}$ \\
\hline Unmodified & 10.11 & 12.80 & 12.90 & 16.87 & 19.30 & 22.22 & 0.0076 & 0.0082 & 0.0088 \\
\hline $\mathrm{CH}_{3} \mathrm{COOH}$ & 76.47 & 79.41 & 88.24 & 487.48 & 578.51 & 1125.51 & 16620.77 & 17609.31 & 20036.03 \\
\hline $\mathrm{NaCl}^{2}$ & 72.86 & 74.28 & 80.00 & 402.69 & 433.23 & 600.00 & 16107.61 & 16808.23 & 18242.14 \\
\hline $\left.\mathrm{NH}_{4}\right)_{2} \mathrm{SO}_{4}$ & 85.71 & 87.14 & 77.14 & 899.67 & 1016.41 & 506.17 & 18266.36 & 19169.61 & 17757.17 \\
\hline $\mathrm{Na}_{2} \mathrm{CO}_{3} .10 \mathrm{H}_{2} \mathrm{O}$ & 60.00 & 61.4 & 65.10 & 225.00 & 238.60 & 279.79 & 14544.52 & 15157.30 & 16066.69 \\
\hline $\mathrm{H}_{2} \mathrm{O}_{2}$ & 23.53 & 27.94 & 30.88 & 46.16 & 58.16 & 67.01 & 10290.57 & 11249.21 & 11991.12 \\
\hline
\end{tabular}

Keys: \% E is Percentage Exhaustion, $\mathrm{K}\left(\mathrm{L} \mathrm{kg}^{-1}\right)$ is Partition Coefficient, $\mathrm{K}$ and $\Delta \mu^{\theta}\left(\mathrm{kJ} \mathrm{mol}^{-1}\right)$ is Standard Affinities.

\subsection{Effects of Temperature on Dyeing}

It is evidently clear from the results illustrated graphically in Figure 3 that temperature change affects dyeing and the percentage dye exhaustion. For instance, when cotton is modified with $1 \% \mathrm{v} / \mathrm{v} \mathrm{CH}_{3} \mathrm{COOH}$; at $323 \mathrm{~K}$ the $\% \mathrm{E}$ is $76.47 \%$ while at $333 \mathrm{~K}$ it is $79.41 \%$ The same progression goes for $\mathrm{NaCl}$, $\left(\mathrm{NH}_{4}\right)_{2} \mathrm{SO}_{4}, \mathrm{Na}_{2} \mathrm{CO}_{3} .10 \mathrm{H}_{2} \mathrm{O}$ and $\mathrm{H}_{2} \mathrm{O}_{2}$ for temperature at $323 \mathrm{~K}$ and $333 \mathrm{~K}$.

Similarly, when the temperature is increased to $343 \mathrm{~K}$ the $\%$ exhaustion equilibrium of the dyes $88.24 \%, 80 \%, 77.14 \%$, $65.10 \%$ and $30.88 \%$ for $\mathrm{CH}_{3} \mathrm{COOH}, \mathrm{NaCl},\left(\mathrm{NH}_{4}\right)_{2} \mathrm{SO}_{4}$,
$\mathrm{Na}_{2} \mathrm{CO}_{3} \cdot 10 \mathrm{H}_{2} \mathrm{O}$ and $\mathrm{H}_{2} \mathrm{O}_{2}$ ' Therefore, $\mathrm{CH}_{3} \mathrm{COOH}$ show highest \% exhaustion while dye $\mathrm{H}_{2} \mathrm{O}_{2}$ gave the lowest percentage exhaustion of $30.88 \%$ at the highest temperature which therefore corresponds to what is reported in the literatures (Bello et al., 2002; 2009). The modifying agents and dye applied to cotton fiber showed high exhaustion at the highest temperature. This is so, because, there is greater segmental mobility of the fiber polymer chains at higher temperatures and this causes penetration of dye molecules into the cotton fiber.

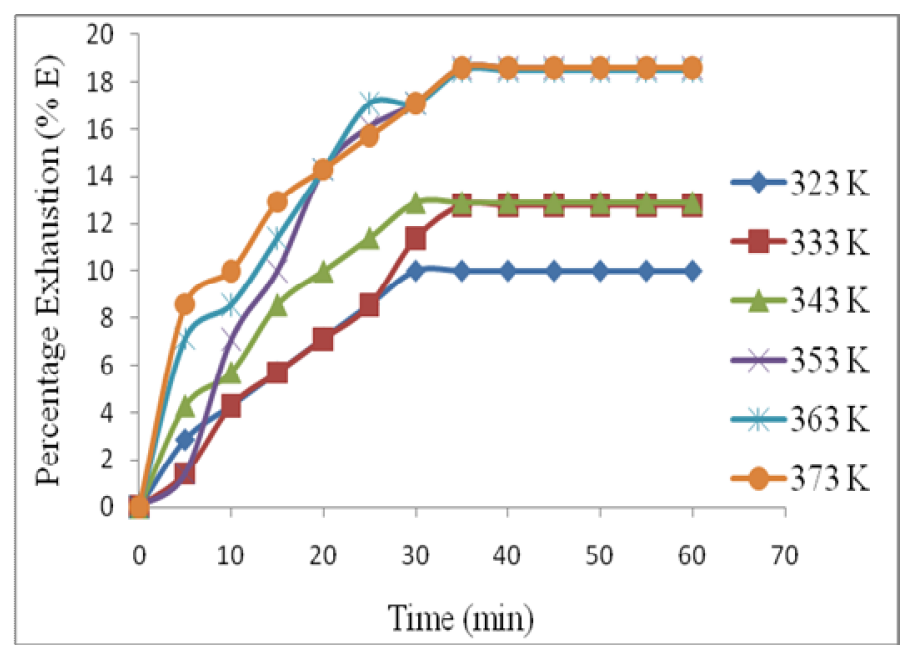

Fig. 1: A Plot of Percentage Equilibrium Exhaustion (\% E) Against Time for Dyeing at Different Temperatures (Without Modification). 

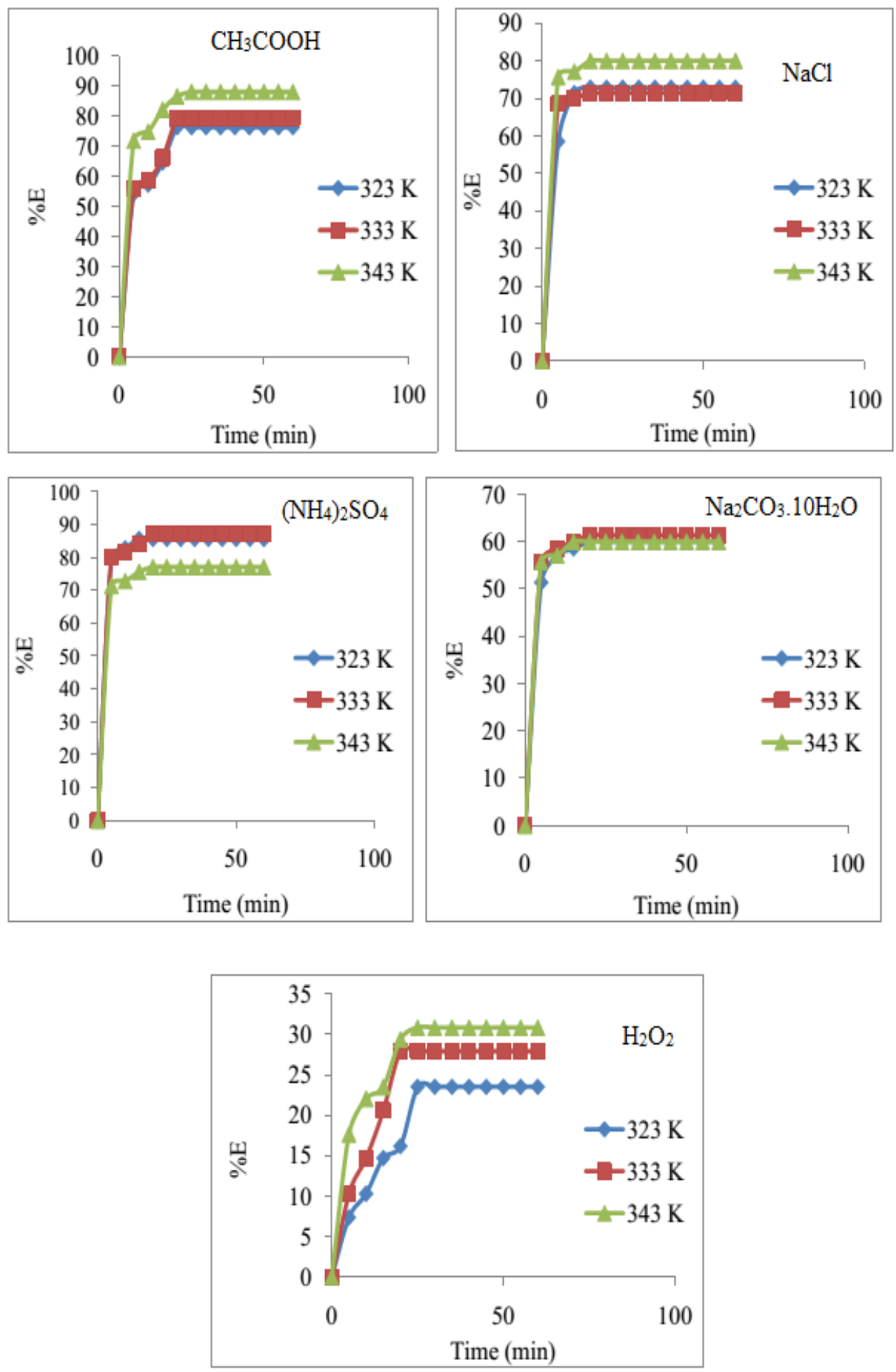

Fig. 2: Effect of different Modifying Agents on Dyed Cotton Fabric at Different Temperature of Dyeing With Modification 

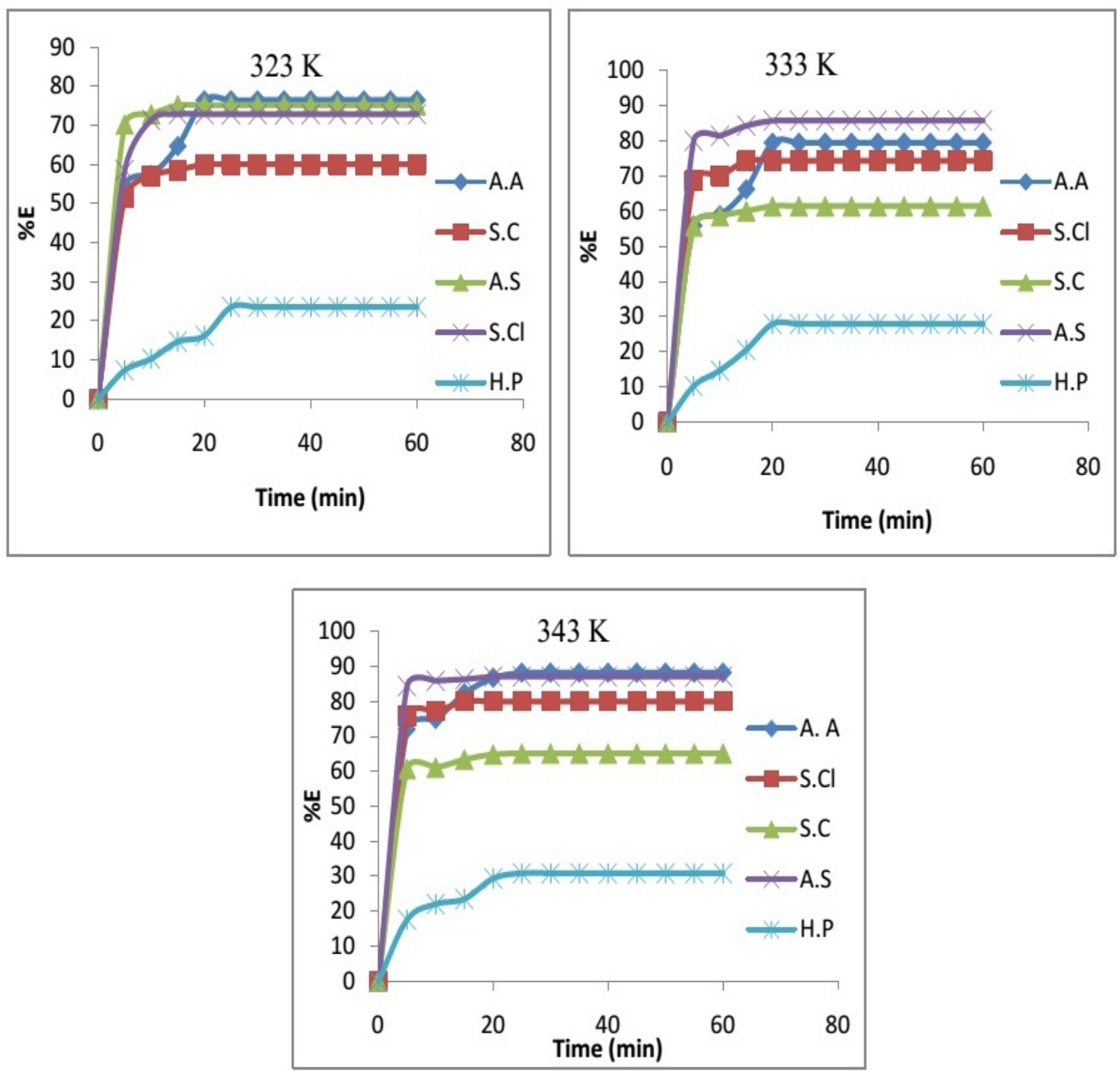

Fig. 3: Effect of time on dyeing exhaustion at $323 \mathrm{~K}$ for $1 \% \mathrm{v} / \mathrm{v}$ modification A.A, S.C, S.Cl, A.S, H.P

Key: A.A: Acetic acid, S.Cl: Sodium Chloride, S.C: Sodium Carbonate, A.S: Ammonium Sulphate, H.P: Hydrogen peroxide.

\subsection{Effects of Time on Modified Cotton}

Figure 3 showed the results of $\% \mathrm{E}$ of modified cotton dyed with malachite green at different time and temperature. Determining of equilibrium time is one of the most characteristics which represent the exhaustion of MG dye on the modified cotton fabric. The Figures 3 indicates that the longer the dyeing time, the greater the amount of dye molecules absorbed by the fiber, until an equilibrium is attained, more dyes penetrate into the polymer at longer dyeing time resulting in high percentage exhaustion and deeper shade (Bello et al., 2014).

The dye exhaustion increases with increasing time to 15 minutes for three modifying agents $\left(\mathrm{Na}_{2} \mathrm{CO}_{3} .10 \mathrm{H}_{2} \mathrm{O},\left(\mathrm{NH}_{4}\right)_{2} \mathrm{SO}_{4}\right)$ and This journal is (C) The Nigerian Young Academy 2017 equilibrium is attained within the 15 minutes whereas, it increases to $20 \mathrm{~min}$ and equilibrium is attained for only two modifying agents $\left(\mathrm{CH}_{3} \mathrm{COOH}\right.$ and $\left.\mathrm{NaCl}\right)$ at $323 \mathrm{~K}$ and 25 mins for $\mathrm{H}_{2} \mathrm{O}_{2}$ before attaining equilibrium. Also at $333 \mathrm{~K}$, time increases to 20 mins and equilibrium is attained for both $\mathrm{CH}_{3} \mathrm{COOH}$, $\mathrm{Na}_{2} \mathrm{CO}_{3} \cdot 1 \mathrm{H}_{2} \mathrm{O},\left(\mathrm{NH}_{4}\right)_{2} \mathrm{SO}_{4}$ and $\mathrm{H}_{2} \mathrm{O}_{2}$ but equilibrium is attained within 15 mins for $\mathrm{NaCl}$. However, at the highest temperature (343 K), the time increases to 20 mins for only one modifying agent (i.e. $\left.\left(\mathrm{NH}_{4}\right)_{2} \mathrm{SO}_{4}\right), 25$ mins for both $\mathrm{CH}_{3} \mathrm{COOH}$, $\mathrm{Na}_{2} \mathrm{CO}_{3} \cdot 10 \mathrm{H}_{2} \mathrm{O}$ and $\mathrm{H}_{2} \mathrm{O}_{2}$ but 15 mins for $\mathrm{NaCl}$. Longer time has no influence on dye exhaustion. This implies that the dye exhaustion reaches equilibrium for different temperatures.

Annals of Science and Technology 2017 Vol. 2(1) 26-35 32 
This observation shows a good agreement with similar work by Burkinshaw and Gotsopoulos, (1999); Bello et al (2002); Adebayo et al., (2010) and Bello et al., (2009). As also shown in Figure 2, \% E values obtained increases as the time increases and afterwards, the $\% \mathrm{E}$ remains constant. The dyeing at the highest temperature gives a high $\% \mathrm{E}$ value. Consequently, increase in time affects dyeing and dye exhaustion thus favours the uptake of dye by the modified fabric until the equilibrium is reached (Bello et al., 2002; Zhang, 2005; Bello et al., 2009; Sundrarajan et al., 2012).

\subsection{Effect of Exhaustion}

The results of the dyeing exhaustion of the modified and unmodified cotton fabric are given in Table 1 It was observed that modified cotton fabric have improved exhaustion compared to the unmodified samples (Schemes 1 and 2). This may be due to the change in the surface morphological structure under modification condition which thus implies that the barrier effect in cotton dyeing is diminished. This can be explained by the fact that the ionic bonds formed between the dyes and the modified cellulose are much stronger than the hydrogen bonds and Van der Waals forces linking the dyes to unmodified cellulose (Kawee and Papapida 1998; Bello et al., 2009, Bello et al., 2014).

For cotton fabrics treated with $\mathrm{CH}_{3} \mathrm{COOH}, \mathrm{Na}_{2} \mathrm{CO}_{3} \cdot 10 \mathrm{H}_{2} \mathrm{O}$, $\mathrm{NaCl},\left(\mathrm{NH}_{4}\right)_{2} \mathrm{SO}_{4}$, and $\mathrm{H}_{2} \mathrm{O}_{2}$, it was observed that the percentage equilibrium exhaustion (\% E) of cotton fabric dyed with Malachite green has improved dye uptake in acidic solution, for instance the $\% \mathrm{E}$ at $343 \mathrm{~K}$ for $\mathrm{CH}_{3} \mathrm{COOH}$ is $88.24 \%$ followed by $\left(\mathrm{NH}_{4}\right)_{2} \mathrm{SO}_{4}(77.14 \%)$ which have ability to undergo hydrolysis in aqueous solution, thereby promotes breaking of the cellulosic chains, reducing the packing of the fibers and thus improves the dye uptake. This then followed closely by neutral solution $\left(\mathrm{NaCl}_{\mathrm{aq}}\right)$ which is $80.00 \%$ and apparently with lower \% $\mathrm{E}$ under alkaline conditions $\left(\mathrm{Na}_{2} \mathrm{CO}_{3} \cdot 10 \mathrm{H}_{2} \mathrm{O}\right)$ which has $65.10 \% \cdot \mathrm{H}_{2} \mathrm{O}_{2}$ having the least $\% \mathrm{E}(30.88 \%)$, due to redox reaction and absent of carbonyl electron withdrawing group unlike $\mathrm{CH}_{3} \mathrm{COOH}$. However, because the bonding force between the nucleophilic group in the dye molecule and the hydroxyl group in the cotton reinforces the electrostatic attraction between the dye and the cationic sites which therefore gave rise to higher percentage exhaustion (\% E). The trend is $\mathrm{CH}_{3} \mathrm{COOH}>\left(\mathrm{NH}_{4}\right)_{2} \mathrm{SO}_{4}>\mathrm{NaCl}>$ $\mathrm{Na}_{2} \mathrm{CO}_{3} \cdot 10 \mathrm{H}_{2} \mathrm{O}>\mathrm{H}_{2} \mathrm{O}_{2}$. The trend is so because the modifying agents suppressed the negative charge on the fiber surface and then allowing reactive dye molecules to diffuse inside the fiber. Also since fixation of reactive dyes onto cellulose fibers requires alkaline dyeing conditions in order to activate the hydroxyl group of cellulose to be able to react with the dye, some of the reactive dye can inevitably undergo the competing hydrolysis reaction with hydroxide nucleophiles thereby resulting in an improved dye uptake by the fiber. This similar to the result obtained by Rattanaphani et al., (2007); Bello et al., (2009); Adebayo et al., (2010), Bello et al., (2013) and Bello et al., (2014)

Figure 4 above show the relationship between $\Delta \mu^{\theta} / \mathrm{T}\left(\mathrm{kJ} \mathrm{mol}^{-1} \mathrm{~K}^{-}\right.$ $\left.{ }^{1}\right)$ and $1 / \mathrm{T}\left(\mathrm{K}^{-1}\right)$ on enthalpy change for the modification of cotton fabric for some thermodynamic parameter $\left(-\Delta \mu^{\theta} / \mathrm{T}\right)$ values obtained from the application of $\mathrm{MG}$ dye on cotton fabric modified with different five modifying agents at three different consecutive temperatures (i.e. $323 \mathrm{~K}, 333 \mathrm{~K}$ and $343 \mathrm{~K}$ ) using the mathematical relation stated in the previous above. The negative values of $\Delta \mathrm{H}^{\theta}$ imply that the reactions were exothermic (Table 4) and that more dye can be retained in the cotton fabric (i.e. dye molecules were strongly embedded within the fiber molecules.. Similar observations were reported by Bello et al., 2002; Bello et al., 2009 and Adebayo et al., 2010.

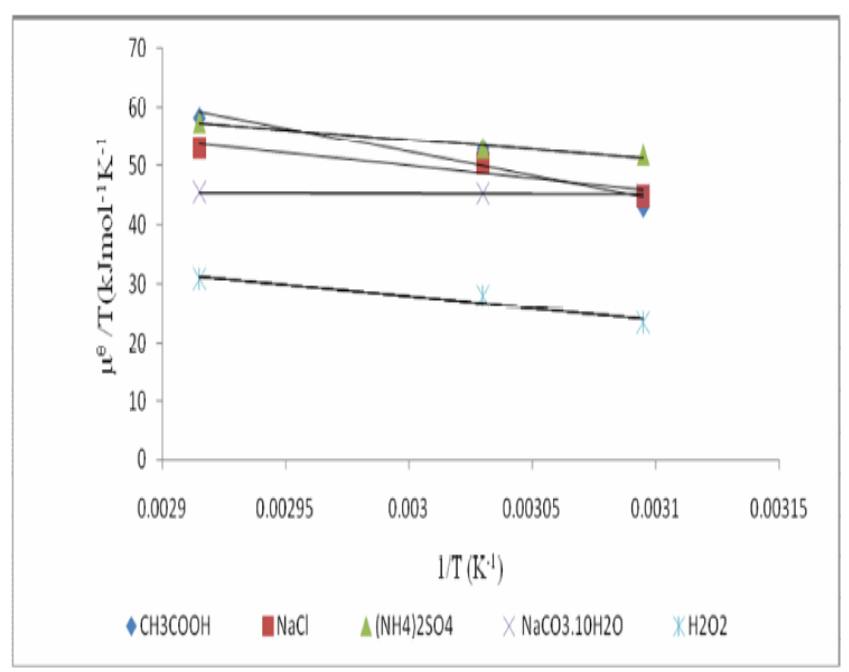

Fig. 4: Relationship between $\Delta \mu^{\theta} / \mathrm{T}\left(\mathrm{kJ} \mathrm{mol}^{-1} \mathrm{~K}^{-1}\right)$ and $1 / \mathrm{T}\left(\mathrm{K}^{-1}\right)$ on Enthalpy Change for the Modification of Cotton Fabric for $1 \% \mathrm{v} / \mathrm{v}$. 


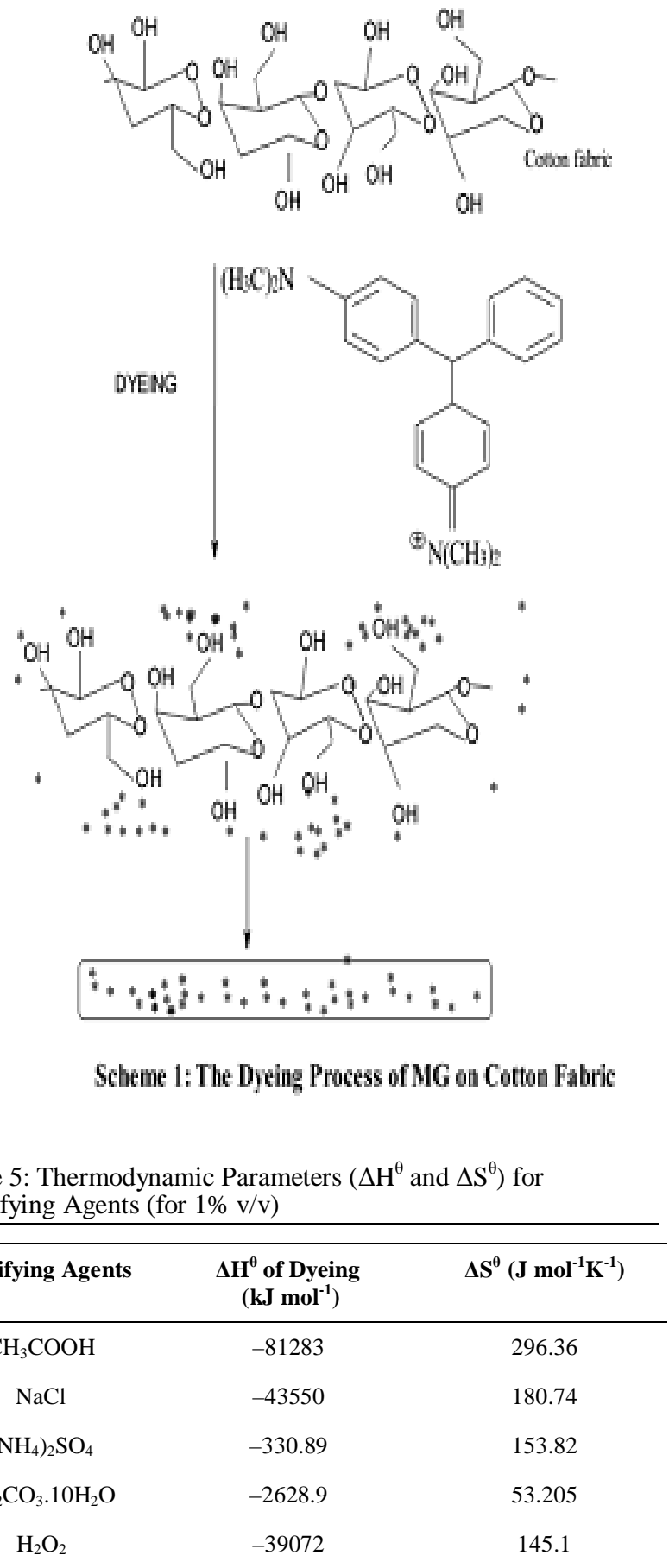

Table 5: Thermodynamic Parameters $\left(\Delta \mathrm{H}^{\theta}\right.$ and $\left.\Delta \mathrm{S}^{\theta}\right)$ for Modifying Agents (for 1\% v/v)

\begin{tabular}{|c|c|c|}
\hline Modifying Agents & $\begin{array}{c}\Delta \mathbf{H}^{\theta} \text { of Dyeing } \\
\left(\mathbf{k J} \mathrm{mol}^{-1}\right)\end{array}$ & $\Delta \mathbf{S}^{\theta}\left(\mathrm{J} \mathrm{mol}^{-1} \mathbf{K}^{-1}\right)$ \\
\hline $\mathrm{CH}_{3} \mathrm{COOH}$ & -81283 & 296.36 \\
\hline $\mathrm{NaCl}$ & -43550 & 180.74 \\
\hline$\left(\mathrm{NH}_{4}\right)_{2} \mathrm{SO}_{4}$ & -330.89 & 153.82 \\
\hline $\mathrm{Na}_{2} \mathrm{CO}_{3} \cdot 10 \mathrm{H}_{2} \mathrm{O}$ & -2628.9 & 53.205 \\
\hline $\mathrm{H}_{2} \mathrm{O}_{2}$ & -39072 & 145.1 \\
\hline
\end{tabular}

\subsection{Conclusion}

The dye uptake of cotton fabric improved after modification. The treatment time and modification power have a greater impact on the dye uptake of the fabric. The dye uptake of modified fabric increases with increasing time until equilibrium is established which means that the longer the time the greater the dye uptake of modified cotton fabric and also resulted into greater dyeability of modified fabric than unmodified one. The optimum temperature is $343 \mathrm{~K}$ with percentage Exhaustion $(\% \mathrm{E})$ of $88.24 \%$, the dye
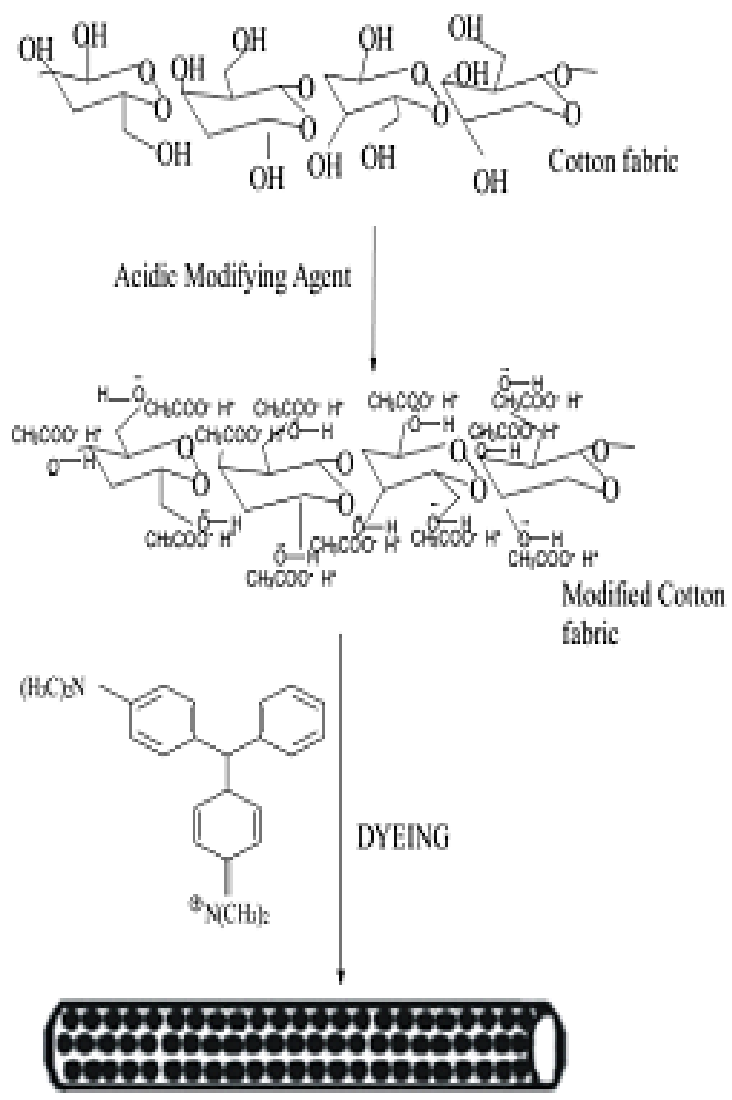

Scheme 2: The Dyeing Process of MG on Modified Cotton Fabric

uptake of modified cotton fabric for the Malachite green dye increased with temperature. This may be a result of increase in the mobility of the large dye ion with temperature. An increasing number of molecules may also acquire sufficient energy to undergo an interaction with active sites at the surface. Furthermore, increasing temperature may produce a swelling effect within the internal structure of the cotton fabric enabling large dyes to penetrate further.

Modification of fabric was an essential criterion to improve the dye uptake and also to reduce the effluent load. If eco-friendly modification agents are used, it will protect the environment from pollution. Such modification agents were used in this study to improve the dyeability of cotton fabric using Malachite green (MG) dye and these are linked on the fabric thereby increased the dye uptake. Modification agents such as $\mathrm{CH}_{3} \mathrm{COOH}$, $\mathrm{Na}_{2} \mathrm{CO}_{3} \cdot 10 \mathrm{H}_{2} \mathrm{O}, \mathrm{NaCl},\left(\mathrm{NH}_{4}\right)_{2} \mathrm{SO}_{4}$ and $\mathrm{H}_{2} \mathrm{O}_{2}$ will be the cost effective environmental friendly approach in the field of dyeing industry. Modification technique therefore has significant potential for industrial application. 


\subsection{Conflict Of Interest}

All Authors have declared that there are no conflicts of interest.

\section{Authors Contribution}

Isah A. Bello and Olugbenga S. Solomon: conception, data analysis and interpretation, correction of the article for important intellectual content and final approval of the published version.

Kayode A. Adegoke: conception, design, data acquisition, data analysis and interpretation, writing and revision of the article.

\subsection{References}

Adebayo, G., Adekola, F., Olatunji, G., Bello, I., 2010, Some thermodynamic parameters of two indigenous mineral dyes applied on wool material. Bulletin of Pure \& Applied Sciences 29, 77.

Baltazar-Y-Jimenez, A., Bismarck, A., 2007, Surface modification of lignocellulosic fibres in atmospheric air pressure plasma. Green Chemistry 9, 1057-1066.

Bashar, M.M., Khan, M.A., 2013, An overview on surface modification of cotton fiber for apparel use. Journal of Polymers and the Environment 21, 181-190.

Bello, I., Bello, K., Peters, O., Bello, O., 2009, Synthesis, Spectroscopic, Thermodynamic And Dyeing Properties Of Disperse Dyes Derived From 2-Amino-4-Trifluoromethylbenzothiazole. Report and Opinion $1,58-66$.

Bello I. A. Peters O. A., Nkeonye P. O. and Sunmonu O. K., 2002, Kinetics and Thermodynamics Studies of an Acid Dye on Modified Nylon 6 Fabrics. J. Pure Appl. Sci., 5: 309-314.

Bello, I.A., Giwa, A.-r.A., Aderinto, S.O., Olabintan, A., 2013, Effect Of Position of Substituents on the Exhaustion and Thermodynamic Parameters of 6 Monoazo Acid and Disperse Dyes on Nylon 6.

Bello I. A., Peters O. A., Giwa A. A., Abdul-Hammed M., Adeoye D. O., 2014, Effect of modifying agents on percentage equilibrium exhaustion of an acid dye on nylon fabric Australian J. Basic Appl. Sci. 8 (1), 552-559

El-Molla, M., Badawy, N., AbdEl-Aal, A., El-Bayaa, A., El-Shaimaa, H., 2011, Dyeability of cationised cotton and nylon 6 fabrics using acid dyes.

Fang, L., Zhang, X., Ma, J., Sun, D., Zhang, B., Luan, J., 2015, Ecofriendly cationic modification of cotton fabrics for improving utilization of reactive dyes. RSC Advances 5, 45654-45661.

Fang, L., Zhang, X., Sun, D., 2013, Chemical modification of cotton fabrics for improving utilization of reactive dyes. Carbohydrate polymers $91,363-369$.
Gharbani, P., Tabatabaii, S., Mehrizad, A., 2008, Removal of Congo red from textile wastewater by ozonation. International Journal of Environmental Science \& Technology 5, 495-500.

Goyal, P., Sharma, P., Srivastava, S., Srivastava, M., 2008, Saraca indica leaf powder for decontamination of $\mathrm{Pb}$ : removal, recovery, adsorbent characterization and equilibrium modeling. International Journal of Environmental Science \& Technology 5, 27-34.

Hasani, M., Westman, G., Potthast, A., Rosenau, T., 2009, Cationization of cellulose by using $\mathrm{N} \square$ oxiranylmethyl $\square \mathrm{N} \square$ methylmorpholinium chloride and $2 \square$ oxiranylpyridine as etherification agents. Journal of applied polymer science $114,1449-1456$.

Hyde, K., Dong, H., Hinestroza, J.P., 2007, Effect of surface cationization on the conformal deposition of polyelectrolytes over cotton fibers. Cellulose 14, 615-623.

Igwe, J.C., Abia, A., Ibeh, C., 2008, Adsorption kinetics and intraparticulate diffusivities of $\mathrm{Hg}, \mathrm{As}$ and $\mathrm{Pb}$ ions on unmodified and thiolated coconut fiber. International Journal of Environmental Science \& Technology 5, 83-92.

Kamel, M., El Zawahry, M., Ahmed, N., Abdelghaffar, F., 2009, Ultrasonic dyeing of cationized cotton fabric with natural dye. Part 1: Cationization of cotton using Solfix E. Ultrasonics Sonochemistry $16,243-249$.

Kawee S. and Papapida P., 1998, Method of Chemical Modification of Cellulosic Fibers to improve their dyeability with reactive dyes J. Sci. Res. Chula. Univ., 23 (2): 143-153

Khattri, S., Singh, M., 1999, Colour removal from dye wastewater using sugar cane dust as an adsorbent. Adsorption science \& technology 17, 269-282.

Liu, Z.-T., Yang, Y., Zhang, L., Liu, Z.-W., Xiong, H., 2007, Study on the cationic modification and dyeing of ramie fiber. Cellulose 14 , 337-345.

Ma, W., Zhang, S., Tang, B., Yang, J., 2005, Pretreatment of cotton with poly (vinylamine chloride) for salt $\square$ free dyeing with reactive dyes. Coloration Technology 121, 193-197.

Mahbubul B. M. and Khan, M.A., 2013, An Overview on Surface Modification of Cotton Fiber for Apparel Use J Polym Environ 21, 181-190.

Mansour R., Farouk M. and Bechir1 E. M., 2014, Dyeing Properties of Cationized and non Cationized Cotton Fabrics Dyed with Vitis vinifera L. Leaves Extract, Middle-East. J. Sci. Res., 21 (9),16001604.

Micheal, M., Tera, F., Ibrahim, S., 2002, Effect of chemical modification of cotton fabrics on dyeing properties. Journal of applied polymer science $85,1897-1903$.

Rattanaphani, S., Chairat, M., Bremner, J.B., Rattanaphani, V., 2007, An adsorption and thermodynamic study of lac dyeing on cotton pretreated with chitosan. Dyes and pigments 72, 88-96.

Rym, M., Farouk, M., Bechir, E.M., 2016, Dyeing properties of cationized and non-cationized cotton fabrics dyed with Vitis vinifera $L$. leaves extract. The Journal of The Textile Institute 107, 525-530. 
Saleh, S.M., El-Badry, K., 2012, Dyeing of cotton/nylon blended fabric to a solid shade in one bath. Global Journal of Science Frontier Research 12.

Shah, B., Shah, A., Singh, R., 2009, Sorption isotherms and kinetics of chromium uptake from wastewater using natural sorbent material. International Journal of Environmental Science \& Technology 6, 7790 .

Shahin, M., 2015, The influence of cationization on the dyeing performance of cotton fabrics with direct dyes. International Journal of Engineering Research and Applications 5, 62-70.

Srikulkit, K., Pornsuriyasak, P., 1998, Method of chemical modification of cellulosic fibers to improve their dyeability with reactive dyes. J Sci Res Chula Univ 23, 143-153.

Sundrarajan, M., Gandhi, R.R., Rukmani, A., Selvam, S., Suresh, J., Gowri, S., 2012, Chitosan and cyclodextrin modification on cellulosic fabric for enhanced natural dyeing. Chemical science transactions 1, 440-446.

Temmerman, E., Leys, C., 2005, Surface modification of cotton yarn with a DC glow discharge in ambient air. Surface and coatings technology 200, 686-689.

Tutak, M., Oktay Özdemir, A., 2011, Reactive dyeing of cationized cotton: effects on the dyeing yield and the fastness properties. Journal of applied polymer science $119,500-504$.

Wang, X.-y., Liu, Y., 2014, The dyeing dynamics and structure of modified cotton fabric with cationic chicken feather keratin agent. Textile Research Journal 84, 561-571.

Xie, K., Hou, A., Sun, Y., 2007, Chemical and morphological structures of modified novel cellulose with triazine derivatives containing cationic and anionic groups. Carbohydrate polymers 70, 285-290.

Xie, K., Hou, A., Wang, X., 2008, Dyeing and diffusion properties of modified novel cellulose with triazine derivatives containing cationic and anionic groups. Carbohydrate polymers 72, 646-651.

ZHANG, J., 2005, New developing trends for dyestuff industry at home and abroad $[\mathrm{J}]$. Dyeing and Finishing 4.

Zvinowanda, C., Okonkwo, J., Shabalala, P., Agyei, N., 2009, A novel adsorbent for heavy metal remediation in aqueous environments. International Journal of Environmental Science \& Technology 6, 425-434. 